\title{
Underdiagnosed Bone Metastatic Cancer in a Patient with Coccygodynia
}

\author{
Yu Mi Kim, So Young Kwon*
}

Dept. of Anesthesiology and Pain Medicine, St. Vincent Hospital, The Catholic University of Korea

\section{INTRODUCTION}

Coccygodynia

: painful condition localized in coccygeal region

referred from rectum, sigmoid colon, urogenitals

$>$ Most common cause : traumatic etiology

$>$ Differentiation : neuropathic / visceral

$>$ Woman $(5: 1)$, obesity(BMI $>27.4$ in females)

- We report a case of coccygeal metastatic cancer that occurred in a patient who had been healthy for 10 years after rectal cancer.

\section{CASE}

\section{$F / 87$}

\section{Chief Complaint}

- Pain in coccygeal and vaginal area (NRS 6)

- Onset : 1 year ago

- Agg. Factor : sitting position

- No related with urination or defication

- No weight loss

\section{Patient History}

- Past history

: rectal cancer s/p Low ant. resection

: complete remission from rectal cancer 10 yrs ago

: no follow-up study

- Traumatic history: none

- Uterine prolapse op. (1 year ago)

\section{Coccyx AP \& Lat. X-ray (Fig.1)}

- No evidence of fracture

- Bone destruction of lower sacrum \& coccyx

\section{Sonogram for Caudal Block}

- Bone irregularity of bony cortex

$\rightarrow$ OS referral

\section{<Orthopedic Surgery Progress Note>}

\section{Bone Scan (Fig.2)}

- Bone meta in sacrum, Rt. Iliac \& pubic bone

\section{MRI (Fig.3)}

- Irregular bone marrow infiltrated lesion in sacrum, epidura extension with encasement of sacral nerve roots

$\rightarrow$ Possible primary bone tumor

$\mathrm{D} / \mathrm{Dx}$; plasmacytoma, metastatic tumor

\section{Admission}

- Cancer work-up : liver meta \& lung meta

- Ix. \& Bx. : metastatic adenocarcinoma

- Decomp. laminectommy \& sacrectomy (Fig.4)

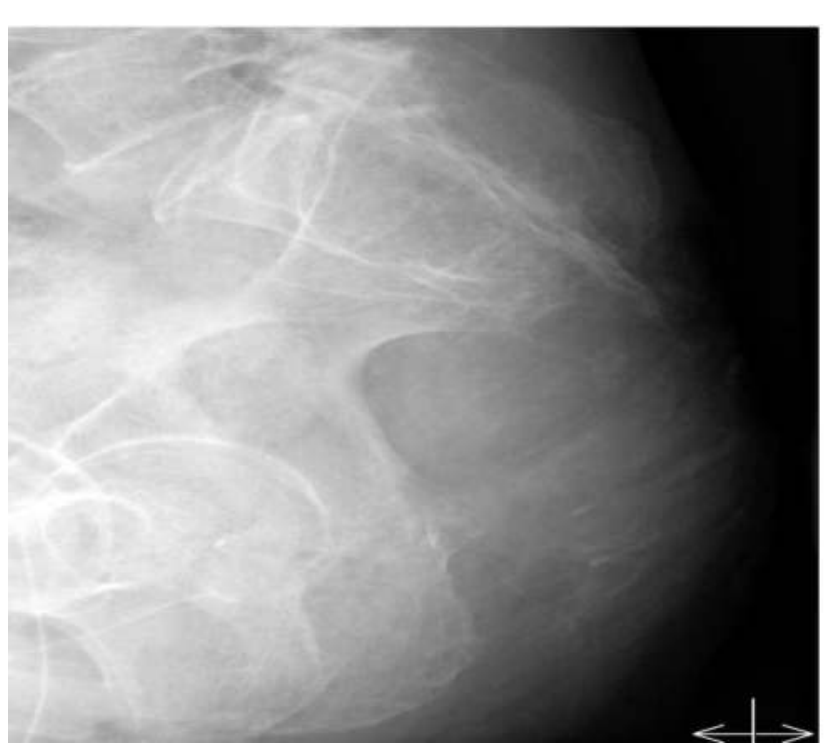

Fig. 1) coccyx Lat.

- bone destruction in lower sacrum \& $\operatorname{cocc} y x$

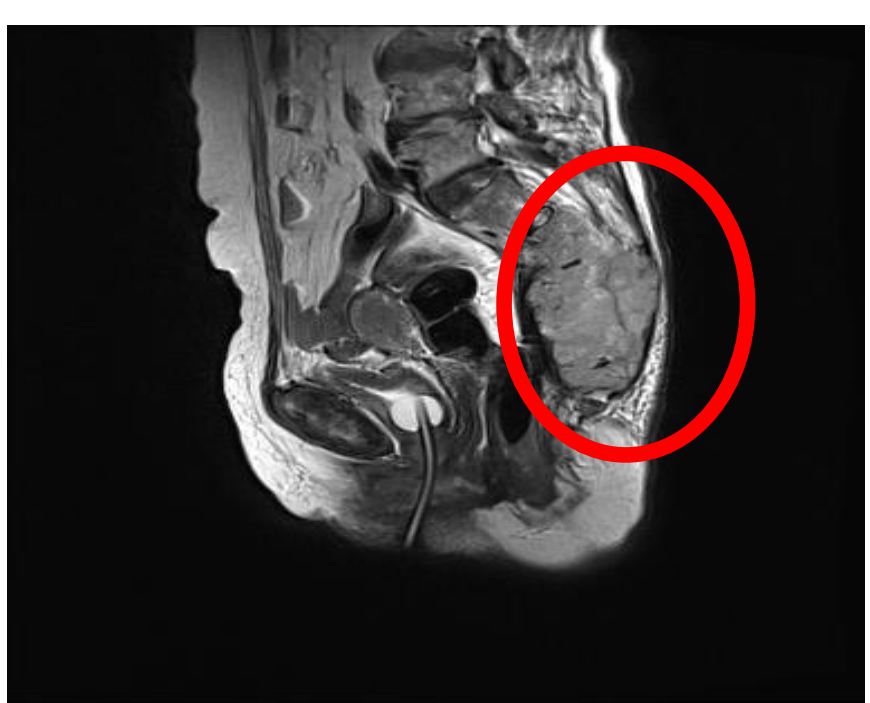

Fig. 3) Pelvic MRI

-irregular bone marrow infiltration in sacrum

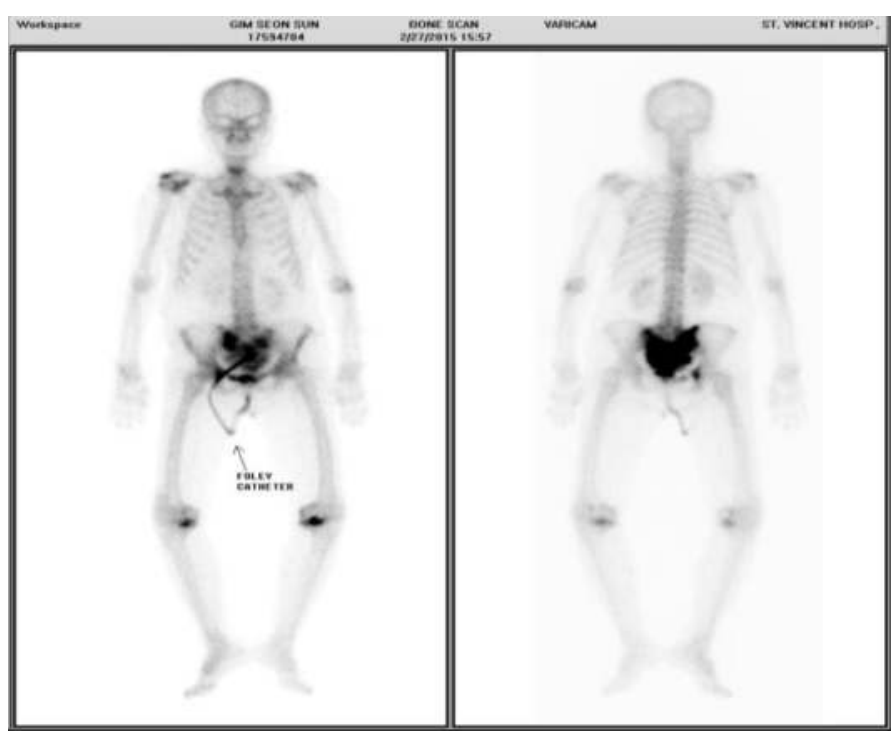

Fig. 2) Bone Scan Rt. Iliac \& pubic bone

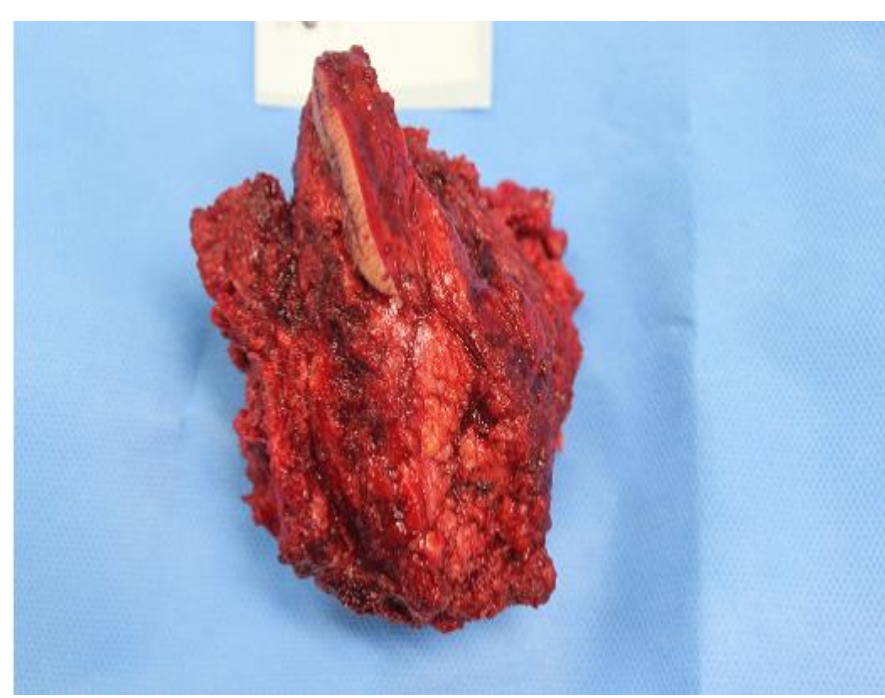

Fig. 4) Sacrectomy \& wide Excision $-8 \times 12 \mathrm{~cm}$ mass lesion involves sacral body

\section{DISCUSSION}

- Coccygodynia from traumatic origin

- Falls in the sitting position

- Microtrama to inadequate body positioning

- Child birth

- Pain provoked by prolonged sitting or cycling

- Neuropathic origin

- Nervous structures are involved

- Lumbar disc herniation

- Schwannomas, neurinoma, arachonoid cyst

- Mixed component

- space-occupying lesion

- Metastasises coccygeal level, chondroma

- Cancer : less common cause of coccygodynia

- Physicians should consider cancer as one of the possible cause of the pain.

- When some causes other than trauma are suspected, more detailed diagnostic procedure and referral are needed.

\section{REFERENCES}

1. Jose De Anderes, and Santiago Chaves, coccygodynia: a proposal for an algorithm for treatment. J Pain 2003;4:257-266

2. Duncan Stewart, P. Kitsanta, J. hampton, asymptomatic isolated coccygeal metastasis in low rectal carcinoma. Tech Coloproctol (2011) 15:349-351 